\title{
Methane and the greenhouse-gas footprint of natural gas from shale formations
}

\section{A letter}

\author{
Robert W. Howarth • Renee Santoro • \\ Anthony Ingraffea
}

Received: 12 November 2010 / Accepted: 13 March 2011 / Published online: 12 April 2011

(C) The Author(s) 2011. This article is published with open access at Springerlink.com

\begin{abstract}
We evaluate the greenhouse gas footprint of natural gas obtained by highvolume hydraulic fracturing from shale formations, focusing on methane emissions. Natural gas is composed largely of methane, and $3.6 \%$ to $7.9 \%$ of the methane from shale-gas production escapes to the atmosphere in venting and leaks over the lifetime of a well. These methane emissions are at least $30 \%$ more than and perhaps more than twice as great as those from conventional gas. The higher emissions from shale gas occur at the time wells are hydraulically fractured-as methane escapes from flow-back return fluids - and during drill out following the fracturing. Methane is a powerful greenhouse gas, with a global warming potential that is far greater than that of carbon dioxide, particularly over the time horizon of the first few decades following emission. Methane contributes substantially to the greenhouse gas footprint of shale gas on shorter time scales, dominating it on a 20 -year time horizon. The footprint for shale gas is greater than that for conventional gas or oil when viewed on any time horizon, but particularly so over 20 years. Compared to coal, the footprint of shale gas is at least $20 \%$ greater and perhaps more than twice as great on the 20 -year horizon and is comparable when compared over 100 years.
\end{abstract}

Keywords Methane - Greenhouse gases • Global warming • Natural gas • Shale gas • Unconventional gas $\cdot$ Fugitive emissions $\cdot$ Lifecycle analysis $\cdot$ LCA $\cdot$ Bridge fuel • Transitional fuel $\cdot$ Global warming potential $\cdot$ GWP

Electronic supplementary material The online version of this article (doi:10.1007/s10584-011-0061-5) contains supplementary material, which is available to authorized users.

R. W. Howarth $(\varangle) \cdot$ R. Santoro

Department of Ecology and Evolutionary Biology, Cornell University, Ithaca, NY 14853, USA e-mail: rwh2@cornell.edu

A. Ingraffea

School of Civil and Environmental Engineering, Cornell University, Ithaca, NY 14853, USA 
Many view natural gas as a transitional fuel, allowing continued dependence on fossil fuels yet reducing greenhouse gas (GHG) emissions compared to oil or coal over coming decades (Pacala and Socolow 2004). Development of "unconventional" gas dispersed in shale is part of this vision, as the potential resource may be large, and in many regions conventional reserves are becoming depleted (Wood et al. 2011). Domestic production in the U.S. was predominantly from conventional reservoirs through the 1990s, but by 2009 U.S. unconventional production exceeded that of conventional gas. The Department of Energy predicts that by 2035 total domestic production will grow by $20 \%$, with unconventional gas providing $75 \%$ of the total (EIA 2010a). The greatest growth is predicted for shale gas, increasing from $16 \%$ of total production in 2009 to an expected $45 \%$ in 2035.

Although natural gas is promoted as a bridge fuel over the coming few decades, in part because of its presumed benefit for global warming compared to other fossil fuels, very little is known about the GHG footprint of unconventional gas. Here, we define the GHG footprint as the total GHG emissions from developing and using the gas, expressed as equivalents of carbon dioxide, per unit of energy obtained during combustion. The GHG footprint of shale gas has received little study or scrutiny, although many have voiced concern. The National Research Council (2009) noted emissions from shale-gas extraction may be greater than from conventional gas. The Council of Scientific Society Presidents (2010) wrote to President Obama, warning that some potential energy bridges such as shale gas have received insufficient analysis and may aggravate rather than mitigate global warming. And in late 2010, the U.S. Environmental Protection Agency issued a report concluding that fugitive emissions of methane from unconventional gas may be far greater than for conventional gas (EPA 2010).

Fugitive emissions of methane are of particular concern. Methane is the major component of natural gas and a powerful greenhouse gas. As such, small leakages are important. Recent modeling indicates methane has an even greater global warming potential than previously believed, when the indirect effects of methane on atmospheric aerosols are considered (Shindell et al. 2009). The global methane budget is poorly constrained, with multiple sources and sinks all having large uncertainties. The radiocarbon content of atmospheric methane suggests fossil fuels may be a far larger source of atmospheric methane than generally thought (Lassey et al. 2007).

The GHG footprint of shale gas consists of the direct emissions of $\mathrm{CO}_{2}$ from enduse consumption, indirect emissions of $\mathrm{CO}_{2}$ from fossil fuels used to extract, develop, and transport the gas, and methane fugitive emissions and venting. Despite the high level of industrial activity involved in developing shale gas, the indirect emissions of $\mathrm{CO}_{2}$ are relatively small compared to those from the direct combustion of the fuel: 1 to $1.5 \mathrm{~g} \mathrm{C} \mathrm{MJ}^{-1}$ (Santoro et al. 2011) vs $15 \mathrm{~g} \mathrm{C} \mathrm{MJ}^{-1}$ for direct emissions (Hayhoe et al. 2002). Indirect emissions from shale gas are estimated to be only 0.04 to $0.45 \mathrm{~g} \mathrm{C} \mathrm{MJ}^{-1}$ greater than those for conventional gas (Wood et al. 2011). Thus, for both conventional and shale gas, the GHG footprint is dominated by the direct $\mathrm{CO}_{2}$ emissions and fugitive methane emissions. Here we present estimates for methane emissions as contributors to the GHG footprint of shale gas compared to conventional gas.

Our analysis uses the most recently available data, relying particularly on a technical background document on GHG emissions from the oil and gas industry (EPA 2010) and materials discussed in that report, and a report on natural gas losses on federal lands from the General Accountability Office (GAO 2010). The 
EPA (2010) report is the first update on emission factors by the agency since 1996 (Harrison et al. 1996). The earlier report served as the basis for the national GHG inventory for the past decade. However, that study was not based on random sampling or a comprehensive assessment of actual industry practices, but rather only analyzed facilities of companies that voluntarily participated (Kirchgessner et al. 1997). The new EPA (2010) report notes that the 1996 "study was conducted at a time when methane emissions were not a significant concern in the discussion about GHG emissions" and that emission factors from the 1996 report "are outdated and potentially understated for some emissions sources." Indeed, emission factors presented in EPA (2010) are much higher, by orders of magnitude for some sources.

\section{Fugitive methane emissions during well completion}

Shale gas is extracted by high-volume hydraulic fracturing. Large volumes of water are forced under pressure into the shale to fracture and re-fracture the rock to boost gas flow. A significant amount of this water returns to the surface as flowback within the first few days to weeks after injection and is accompanied by large quantities of methane (EPA 2010). The amount of methane is far more than could be dissolved in the flow-back fluids, reflecting a mixture of fracture-return fluids and methane gas. We have compiled data from 2 shale gas formations and 3 tightsand gas formations in the U.S. Between $0.6 \%$ and $3.2 \%$ of the life-time production of gas from wells is emitted as methane during the flow-back period (Table 1). We include tight-sand formations since flow-back emissions and the patterns of gas production over time are similar to those for shale (EPA 2010). Note that the rate of methane emitted during flow-back (column B in Table 1) correlates well to the initial production rate for the well following completion (column $\mathrm{C}$ in Table 1). Although the data are limited, the variation across the basins seems reasonable: the highest methane emissions during flow-back were in the Haynesville, where initial pressures and initial production were very high, and the lowest emissions were in the Uinta, where the flow-back period was the shortest and initial production following well completion was low. However, we note that the data used in Table 1 are not well documented, with many values based on PowerPoint slides from EPA-sponsored workshops. For this paper, we therefore choose to represent gas losses from flowback fluids as the mean value from Table $1: 1.6 \%$.

More methane is emitted during "drill-out," the stage in developing unconventional gas in which the plugs set to separate fracturing stages are drilled out to release gas for production. EPA (2007) estimates drill-out emissions at $142 \times 10^{3}$ to $425 \times$ $10^{3} \mathrm{~m}^{3}$ per well. Using the mean drill-out emissions estimate of $280 \times 10^{3} \mathrm{~m}^{3}$ (EPA 2007) and the mean life-time gas production for the 5 formations in Table $1(85 \times$ $10^{6} \mathrm{~m}^{3}$ ), we estimate that $0.33 \%$ of the total life-time production of wells is emitted as methane during the drill-out stage. If we instead use the average life-time production for a larger set of data on 12 formations (Wood et al. 2011), $45 \times 10^{6} \mathrm{~m}^{3}$, we estimate a percentage emission of $0.62 \%$. More effort is needed to determine drill-out emissions on individual formation. Meanwhile, in this paper we use the conservative estimate of $0.33 \%$ for drill-out emissions.

Combining losses associated with flow-back fluids (1.6\%) and drill out $(0.33 \%)$, we estimate that $1.9 \%$ of the total production of gas from an unconventional shale-gas 


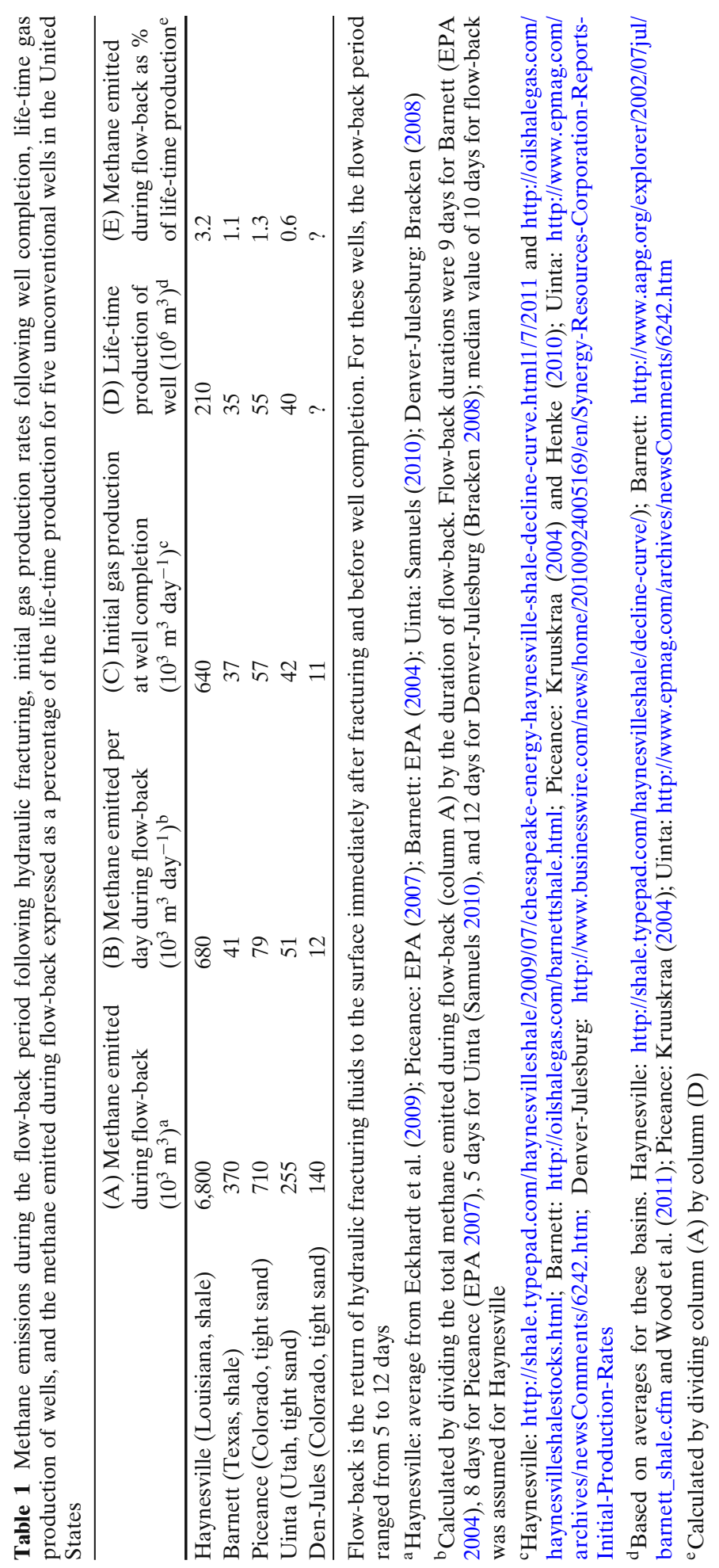


Table 2 Fugitive methane emissions associated with development of natural gas from conventional wells and from shale formations (expressed as the percentage of methane produced over the lifecycle of a well)

\begin{tabular}{lll}
\hline & Conventional gas & Shale gas \\
\hline Emissions during well completion & $0.01 \%$ & $1.9 \%$ \\
Routine venting and equipment leaks at well site & 0.3 to $1.9 \%$ & 0.3 to $1.9 \%$ \\
Emissions during liquid unloading & 0 to $0.26 \%$ & 0 to $0.26 \%$ \\
Emissions during gas processing & 0 to $0.19 \%$ & 0 to $0.19 \%$ \\
Emissions during transport, storage, and distribution & 1.4 to $3.6 \%$ & 1.4 to $3.6 \%$ \\
Total emissions & 1.7 to $6.0 \%$ & 3.6 to $7.9 \%$ \\
\hline
\end{tabular}

See text for derivation of estimates and supporting information

well is emitted as methane during well completion (Table 2). Again, this estimate is uncertain but conservative.

Emissions are far lower for conventional natural gas wells during completion, since conventional wells have no flow-back and no drill out. An average of $1.04 \times$ $10^{3} \mathrm{~m}^{3}$ of methane is released per well completed for conventional gas (EPA 2010), corresponding to $1.32 \times 10^{3} \mathrm{~m}^{3}$ natural gas (assuming $78.8 \%$ methane content of the gas). In 2007, 19,819 conventional wells were completed in the US (EPA 2010), so we estimate a total national emission of $26 \times 10^{6} \mathrm{~m}^{3}$ natural gas. The total national production of onshore conventional gas in 2007 was $384 \times 10^{9} \mathrm{~m}^{3}$ (EIA 2010b). Therefore, we estimate the average fugitive emissions at well completion for conventional gas as $0.01 \%$ of the life-time production of a well (Table 2), three orders of magnitude less than for shale gas.

\section{Routine venting and equipment leaks}

After completion, some fugitive emissions continue at the well site over its lifetime. A typical well has 55 to 150 connections to equipment such as heaters, meters, dehydrators, compressors, and vapor-recovery apparatus. Many of these potentially leak, and many pressure relief valves are designed to purposefully vent gas. Emissions from pneumatic pumps and dehydrators are a major part of the leakage (GAO 2010). Once a well is completed and connected to a pipeline, the same technologies are used for both conventional and shale gas; we assume that these post-completion fugitive emissions are the same for shale and conventional gas. GAO (2010) concluded that $0.3 \%$ to $1.9 \%$ of the life-time production of a well is lost due to routine venting and equipment leaks (Table 2). Previous studies have estimated routine well-site fugitive emissions as approximately $0.5 \%$ or less (Hayhoe et al. 2002; Armendariz 2009) and $0.95 \%$ (Shires et al. 2009). Note that none of these estimates include accidents or emergency vents. Data on emissions during emergencies are not available and have never, as far as we can determine, been used in any estimate of emissions from natural gas production. Thus, our estimate of $0.3 \%$ to $1.9 \%$ leakage is conservative. As we discuss below, the $0.3 \%$ reflects use of best available technology.

Additional venting occurs during "liquid unloading." Conventional wells frequently require multiple liquid-unloading events as they mature to mitigate water intrusion as reservoir pressure drops. Though not as common, some unconventional wells may also require unloading. Empirical data from 4 gas basins indicate that 0.02 
to $0.26 \%$ of total life-time production of a well is vented as methane during liquid unloading (GAO 2010). Since not all wells require unloading, we set the range at 0 to $0.26 \%$ (Table 2 ).

\section{Processing losses}

Some natural gas, whether conventional or from shale, is of sufficient quality to be "pipeline ready" without further processing. Other gas contains sufficient amounts of heavy hydrocarbons and impurities such as sulfur gases to require removal through processing before the gas is piped. Note that the quality of gas can vary even within a formation. For example, gas from the Marcellus shale in northeastern Pennsylvania needs little or no processing, while gas from southwestern Pennsylvania must be processed (NYDEC 2009). Some methane is emitted during this processing. The default EPA facility-level fugitive emission factor for gas processing indicates a loss of $0.19 \%$ of production (Shires et al. 2009). We therefore give a range of $0 \%$ (i.e. no processing, for wells that produce "pipeline ready" gas) to $0.19 \%$ of gas produced as our estimate of processing losses (Table 2). Actual measurements of processing plant emissions in Canada showed fourfold greater leakage than standard emission factors of the sort used by Shires et al. (2009) would indicate (Chambers 2004), so again, our estimates are very conservative.

\section{Transport, storage, and distribution losses}

Further fugitive emissions occur during transport, storage, and distribution of natural gas. Direct measurements of leakage from transmission are limited, but two studies give similar leakage rates in both the U.S. (as part of the 1996 EPA emission factor study; mean value of $0.53 \%$; Harrison et al. 1996; Kirchgessner et al. 1997) and in Russia ( $0.7 \%$ mean estimate, with a range of $0.4 \%$ to $1.6 \%$; Lelieveld et al. 2005). Direct estimates of distribution losses are even more limited, but the 1996 EPA study estimates losses at $0.35 \%$ of production (Harrison et al. 1996; Kirchgessner et al. 1997). Lelieveld et al. (2005) used the 1996 emission factors for natural gas storage and distribution together with their transmission estimates to suggest an overall average loss rate of $1.4 \%$ (range of $1.0 \%$ to $2.5 \%$ ). We use this $1.4 \%$ leakage as the likely lower limit (Table 2). As noted above, the EPA 1996 emission estimates are based on limited data, and Revkin and Krauss (2009) reported "government scientists and industry officials caution that the real figure is almost certainly higher." Furthermore, the IPCC (2007) cautions that these "bottom-up" approaches for methane inventories often underestimate fluxes.

Another way to estimate pipeline leakage is to examine "lost and unaccounted for gas," e.g. the difference between the measured volume of gas at the wellhead and that actually purchased and used by consumers. At the global scale, this method has estimated pipeline leakage at $2.5 \%$ to $10 \%$ (Crutzen 1987; Cicerone and Oremland 1988; Hayhoe et al. 2002), although the higher value reflects poorly maintained pipelines in Russia during the Soviet collapse, and leakages in Russia are now far less (Lelieveld et al. 2005; Reshetnikov et al. 2000). Kirchgessner et al. (1997) argue against this approach, stating it is "subject to numerous errors including gas theft, variations in 
temperature and pressure, billing cycle differences, and meter inaccuracies." With the exception of theft, however, errors should be randomly distributed and should not bias the leakage estimate high or low. Few recent data on lost and unaccounted gas are publicly available, but statewide data for Texas averaged $2.3 \%$ in 2000 and $4.9 \%$ in 2007 (Percival 2010). In 2007, the State of Texas passed new legislation to regulate lost and unaccounted for gas; the legislation originally proposed a $5 \%$ hard cap which was dropped in the face of industry opposition (Liu 2008; Percival 2010). We take the mean of the 2000 and 2007 Texas data for missing and unaccounted gas $(3.6 \%)$ as the upper limit of downstream losses (Table 2), assuming that the higher value for 2007 and lower value for 2000 may potentially reflect random variation in billing cycle differences. We believe this is a conservative upper limit, particularly given the industry resistance to a $5 \%$ hard cap.

Our conservative estimate of $1.4 \%$ to $3.6 \%$ leakage of gas during transmission, storage, and distribution is remarkably similar to the $2.5 \%$ "best estimate" used by Hayhoe et al. (2002). They considered the possible range as $0.2 \%$ and $10 \%$.

\section{Contribution of methane emissions to the GHG footprints of shale gas and conventional gas}

Summing all estimated losses, we calculate that during the life cycle of an average shale-gas well, 3.6 to $7.9 \%$ of the total production of the well is emitted to the atmosphere as methane (Table 2). This is at least 30\% more and perhaps more than twice as great as the life-cycle methane emissions we estimate for conventional gas, $1.7 \%$ to $6 \%$. Methane is a far more potent $\mathrm{GHG}$ than is $\mathrm{CO}_{2}$, but methane also has a tenfold shorter residence time in the atmosphere, so its effect on global warming attenuates more rapidly (IPCC 2007). Consequently, to compare the global warming potential of methane and $\mathrm{CO}_{2}$ requires a specific time horizon. We follow Lelieveld et al. (2005) and present analyses for both 20-year and 100-year time horizons. Though the 100-year horizon is commonly used, we agree with Nisbet et al. (2000) that the 20-year horizon is critical, given the need to reduce global warming in coming decades (IPCC 2007). We use recently modeled values for the global warming potential of methane compared to $\mathrm{CO}_{2}: 105$ and 33 on a mass-to-mass basis for 20 and 100 years, respectively, with an uncertainty of plus or minus $23 \%$ (Shindell et al. 2009). These are somewhat higher than those presented in the 4 th assessment report of the IPCC (2007), but better account for the interaction of methane with aerosols. Note that carbon-trading markets use a lower global-warming potential yet of only 21 on the 100-year horizon, but this is based on the 2nd IPCC (1995) assessment, which is clearly out of date on this topic. See Electronic Supplemental Materials for the methodology for calculating the effect of methane on GHG in terms of $\mathrm{CO}_{2}$ equivalents.

Methane dominates the GHG footprint for shale gas on the 20-year time horizon, contributing 1.4- to 3-times more than does direct $\mathrm{CO}_{2}$ emission (Fig. 1a). At this time scale, the GHG footprint for shale gas is $22 \%$ to $43 \%$ greater than that for conventional gas. When viewed at a time 100 years after the emissions, methane emissions still contribute significantly to the GHG footprints, but the effect is diminished by the relatively short residence time of methane in the atmosphere. On this time frame, the GHG footprint for shale gas is $14 \%$ to $19 \%$ greater than that for conventional gas (Fig. 1b). 


\section{A. 20-year time horizon}

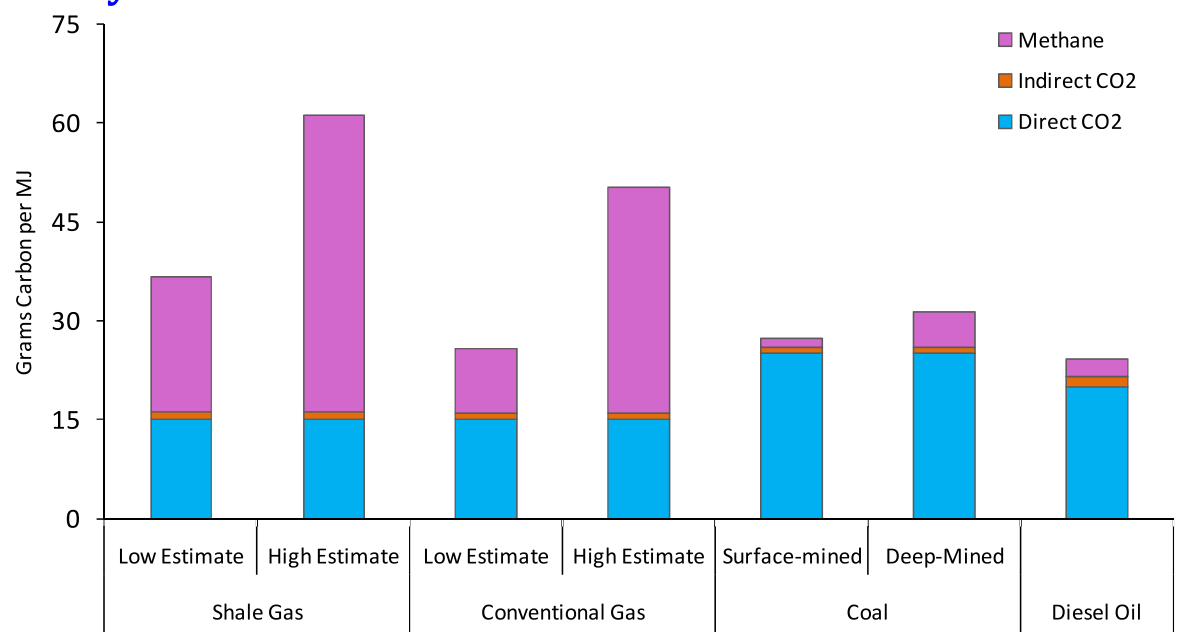

\section{B. 100-year time horizon}

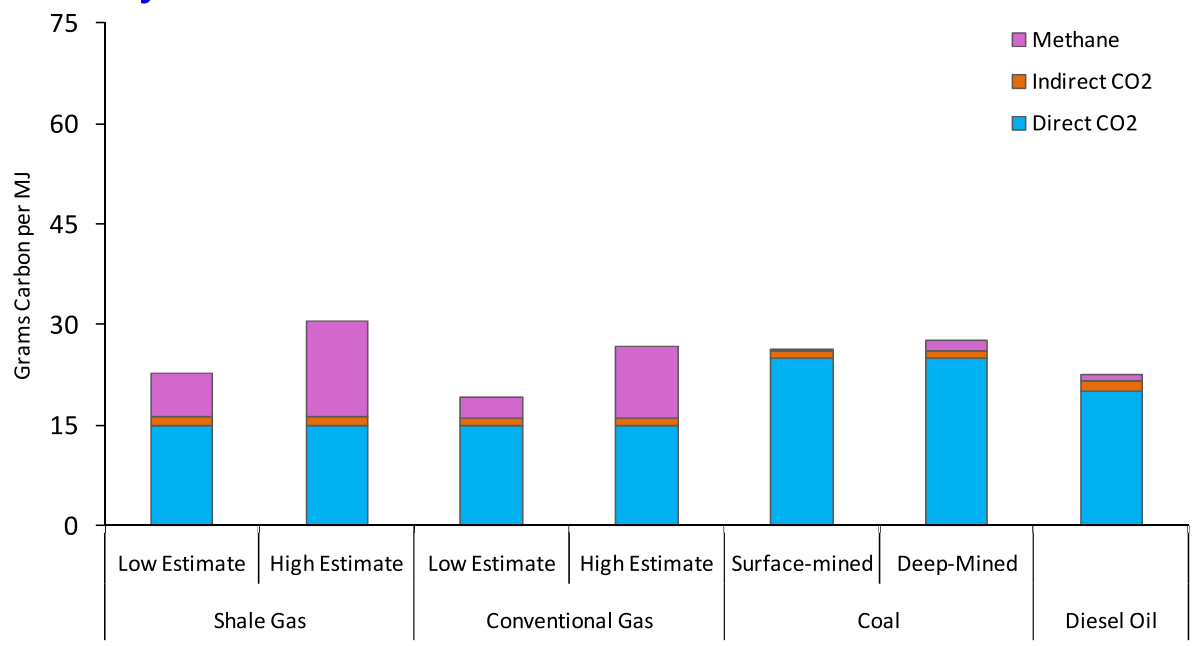

Fig. 1 Comparison of greenhouse gas emissions from shale gas with low and high estimates of fugitive methane emissions, conventional natural gas with low and high estimates of fugitive methane emissions, surface-mined coal, deep-mined coal, and diesel oil. a is for a 20 -year time horizon, and b is for a 100-year time horizon. Estimates include direct emissions of $\mathrm{CO}_{2}$ during combustion (blue bars), indirect emissions of $\mathrm{CO}_{2}$ necessary to develop and use the energy source (red bars), and fugitive emissions of methane, converted to equivalent value of $\mathrm{CO}_{2}$ as described in the text (pink bars). Emissions are normalized to the quantity of energy released at the time of combustion. The conversion of methane to $\mathrm{CO}_{2}$ equivalents is based on global warming potentials from Shindell et al. (2009) that include both direct and indirect influences of methane on aerosols. Mean values from Shindell et al. (2009) are used here. Shindell et al. (2009) present an uncertainty in these mean values of plus or minus $23 \%$, which is not included in this figure 


\section{Shale gas versus other fossil fuels}

Considering the 20-year horizon, the GHG footprint for shale gas is at least $20 \%$ greater than and perhaps more than twice as great as that for coal when expressed per quantity of energy available during combustion (Fig. 1a; see Electronic Supplemental Materials for derivation of the estimates for diesel oil and coal). Over the 100-year frame, the GHG footprint is comparable to that for coal: the low-end shale-gas emissions are $18 \%$ lower than deep-mined coal, and the high-end shale-gas emissions are $15 \%$ greater than surface-mined coal emissions (Fig. 1b). For the 20 year horizon, the GHG footprint of shale gas is at least $50 \%$ greater than for oil, and perhaps 2.5 times greater. At the 100-year time scale, the footprint for shale gas is similar to or $35 \%$ greater than for oil.

We know of no other estimates for the GHG footprint of shale gas in the peerreviewed literature. However, we can compare our estimates for conventional gas with three previous peer-reviewed studies on the GHG emissions of conventional natural gas and coal: Hayhoe et al. (2002), Lelieveld et al. (2005), and Jamarillo et al. (2007). All concluded that GHG emissions for conventional gas are less than for coal, when considering the contribution of methane over 100 years. In contrast, our analysis indicates that conventional gas has little or no advantage over coal even over the 100-year time period (Fig. 1b). Our estimates for conventional-gas methane emissions are in the range of those in Hayhoe et al. (2002) but are higher than those in Lelieveld et al. (2005) and Jamarillo et al. (2007) who used 1996 EPA emission factors now known to be too low (EPA 2010). To evaluate the effect of methane, all three of these studies also used global warming potentials now believed to be too low (Shindell et al. 2009). Still, Hayhoe et al. (2002) concluded that under many of the scenarios evaluated, a switch from coal to conventional natural gas could aggravate global warming on time scales of up to several decades. Even with the lower global warming potential value, Lelieveld et al. (2005) concluded that natural gas has a greater GHG footprint than oil if methane emissions exceeded $3.1 \%$ and worse than coal if the emissions exceeded $5.6 \%$ on the 20 -year time scale. They used a methane global warming potential value for methane from IPCC (1995) that is only 57\% of the new value from Shindell et al. (2009), suggesting that in fact methane emissions of only $2 \%$ to $3 \%$ make the GHG footprint of conventional gas worse than oil and coal. Our estimates for fugitive shale-gas emissions are 3.6 to $7.9 \%$.

Our analysis does not consider the efficiency of final use. If fuels are used to generate electricity, natural gas gains some advantage over coal because of greater efficiencies of generation (see Electronic Supplemental Materials). However, this does not greatly affect our overall conclusion: the GHG footprint of shale gas approaches or exceeds coal even when used to generate electricity (Table in Electronic Supplemental Materials). Further, shale-gas is promoted for other uses, including as a heating and transportation fuel, where there is little evidence that efficiencies are superior to diesel oil.

\section{Can methane emissions be reduced?}

The EPA estimates that 'green' technologies can reduce gas-industry methane emissions by $40 \%$ (GAO 2010). For instance, liquid-unloading emissions can be greatly 
reduced with plunger lifts (EPA 2006; GAO 2010); industry reports a 99\% venting reduction in the San Juan basin with the use of smart-automated plunger lifts (GAO 2010). Use of flash-tank separators or vapor recovery units can reduce dehydrator emissions by $90 \%$ (Fernandez et al. 2005). Note, however, that our lower range of estimates for 3 out of the 5 sources as shown in Table 2 already reflect the use of best technology: $0.3 \%$ lower-end estimate for routine venting and leaks at well sites (GAO 2010), 0\% lower-end estimate for emissions during liquid unloading, and 0\% during processing.

Methane emissions during the flow-back period in theory can be reduced by up to 90\% through Reduced Emission Completions technologies, or REC (EPA 2010). However, REC technologies require that pipelines to the well are in place prior to completion, which is not always possible in emerging development areas. In any event, these technologies are currently not in wide use (EPA 2010).

If emissions during transmission, storage, and distribution are at the high end of our estimate (3.6\%; Table 2), these could probably be reduced through use of better storage tanks and compressors and through improved monitoring for leaks. Industry has shown little interest in making the investments needed to reduce these emission sources, however (Percival 2010).

Better regulation can help push industry towards reduced emissions. In reconciling a wide range of emissions, the GAO (2010) noted that lower emissions in the Piceance basin in Colorado relative to the Uinta basin in Utah are largely due to a higher use of low-bleed pneumatics in the former due to stricter state regulations.

\section{Conclusions and implications}

The GHG footprint of shale gas is significantly larger than that from conventional gas, due to methane emissions with flow-back fluids and from drill out of wells during well completion. Routine production and downstream methane emissions are also large, but are the same for conventional and shale gas. Our estimates for these routine and downstream methane emission sources are within the range of those reported by most other peer-reviewed publications inventories (Hayhoe et al. 2002; Lelieveld et al.2005). Despite this broad agreement, the uncertainty in the magnitude of fugitive emissions is large. Given the importance of methane in global warming, these emissions deserve far greater study than has occurred in the past. We urge both more direct measurements and refined accounting to better quantify lost and unaccounted for gas.

The large GHG footprint of shale gas undercuts the logic of its use as a bridging fuel over coming decades, if the goal is to reduce global warming. We do not intend that our study be used to justify the continued use of either oil or coal, but rather to demonstrate that substituting shale gas for these other fossil fuels may not have the desired effect of mitigating climate warming.

Finally, we note that carbon-trading markets at present under-value the greenhouse warming consequences of methane, by focusing on a 100-year time horizon and by using out-of-date global warming potentials for methane. This should be corrected, and the full GHG footprint of unconventional gas should be used in planning for alternative energy futures that adequately consider global climate change. 
Acknowledgements Preparation of this paper was supported by a grant from the Park Foundation and by an endowment funds of the David R. Atkinson Professorship in Ecology \& Environmental Biology at Cornell University. We thank R. Alvarez, C. Arnold, P. Artaxo, A. Chambers, D. Farnham, P. Jamarillo, N. Mahowald, R. Marino, R. McCoy, J. Northrup, S. Porder, M. Robertson, B. Sell, D. Shrag, L. Spaeth, and D. Strahan for information, encouragement, advice, and feedback on our analysis and manuscript. We thank M. Hayn for assistance with the figures. Two anonymous reviewers and Michael Oppenheimer provided very useful comments on an earlier version of this paper.

Open Access This article is distributed under the terms of the Creative Commons Attribution Noncommercial License which permits any noncommercial use, distribution, and reproduction in any medium, provided the original author(s) and source are credited.

\section{References}

Armendariz A (2009) Emissions from natural gas production in the Barnett shale area and opportunities for cost-effective improvements. Report prepared for Environmental Defense Fund, Austin TX

Bracken K (2008) Reduced emission completions in DJ basin and natural buttes. Presentation given at EPA/GasSTAR Producers Technology Transfer Workshop. Rock Springs Wyoming, 1 May 2008. http://www.epa.gov/gasstar/documents/workshops/2008-tech-transfer/rocksprings5.pdf

Chambers AK (2004) Optical measurement technology for fugitive emissions from upstream oil and gas facilities. Report prepared for Petroleum Technology Alliance Canada by Carbon and Energy Management, Alberta Research Council, Edmonton, Alberta

Cicerone RJ, Oremland R (1988) Biogeochemical aspects of atmospheric methane. Global Biogeochem. Cycles 2:299-327

Council of Scientific Society Presidents (2010) Letter from the council to President Obama and senior administration officials, dated May 4, 2010. Council of Scientific Society Presidents, 1155 16th Avenue NW, Washington, DC 20036. Available at http://www.eeb.cornell.edu/ howarth/CCSP\%20letter\%20on\%20energy\%20\&\%20environment.pdf

Crutzen PJ (1987) Role of the tropics in atmospheric chemistry. In: Dickinson R (ed) Geophysiology of Amazonia. Wiley, NY, pp 107-129

Eckhardt M, Knowles B, Maker E, Stork P (2009) IHS U.S. Industry Highlights. (IHS) Houston, TX, Feb-Mar 2009. http://www.gecionline.com/2009-prt-7-final-reviews

EIA (2010a) Annual energy outlook 2011 early release overview. DOE/EIA-0383ER(2011). Energy Information Agency, U.S. Department of Energy. http://www.eia.gov/forecasts/aeo/pdf/ 0383er(2011).pdf. Accessed 3 January 2011

EIA (2010b) Natural gas navigator. Natural gas gross withdrawals and production. http://www. eia.gov/dnav/ng/ng_prod_sum_dcu_NUS_m.htm

EPA (2004) Green completions. Natural Gas STAR Producer's Technology Transfer Workshop, 21 September 2004. http://epa.gov/gasstar/workshops/techtransfer/2004/houston-02.html

EPA (2006) Lessons learned: options for reducing methane emissions from pneumatic devices in the natural gas industry. U.S. EPA/ Gas STAR. http://www.epa.gov/gasstar/documents/l_ pneumatics.pdf

EPA (2007) Reducing methane emissions during completion operations. Natural Gas STAR Producer's Technology Transfer Workshop, 11 September 2007. http://epa.gov/gasstar/documents/ workshops/glenwood-2007/04_recs.pdf

EPA (2010) Greenhouse gas emissions reporting from the petroleum and natural gas industry. Background Technical Support Document. http://www.epa.gov/climatechange/emissions/ downloads10/Subpart-W_TSD.pdf. Accessed 3 January 2011

Fernandez R, Petrusak R, Robinson D, Zavadil D (2005) Cost-Effective methane emissions reductions for small and midsize natural gas producers. Reprinted from the June 2005 issue of Journal of Petroleum Technology. http://www.icfi.com/Markets/Environment/doc_files/ methane-emissions.pdf

GAO (2010) Federal oil and gas leases: opportunities exist to capture vented and flared natural gas, which would increase royalty payments and reduce greenhouse gases. GAO-11-34 U.S. General Accountability Office Washington DC. http://www.gao.gov/new.items/d1134.pdf 
Harrison MR, Shires TM, Wessels JK, Cowgill RM (1996) Methane emissions from the natural gas industry. Executive summary, vol 1. EPA-600/R-96-080a. U.S. Environmental Protection Agency, Office of Research and Development, Washington, DC

Hayhoe K, Kheshgi HS, Jain AK, Wuebbles DJ (2002) Substitution of natural gas for coal: climatic effects of utility sector emissions. Climatic Change 54:107-139

Henke D (2010) Encana, USA division overview. Encana Natural Gas, investors presentation. http://www.encana.com/investors/presentations/investorday/pdfs/usa-division-overview.pdf

Intergovernmental Panel on Climate Change (1995) IPCC second assessment. Climate Change, 1995. http://www.ipcc.ch/pdf/climate-changes-1995/ipcc-2nd-assessment/2nd-assessment-en.pdf

Intergovernmental Panel on Climate Change (2007) IPCC fourth assessment report (AR4). Working Group 1, The Physical Science Basis. http://www.ipcc.ch/publications_and_data/ar4/wg1/ en/contents.html

Jamarillo P, Griffin WM, Mathews HS (2007) Comparative life-cycle air emissions of coal, domestic natural gas, LNG, and SNG for electricity generation. Environ Sci Technol 41:6290-6296

Kirchgessner DA, Lott RA, Cowgill RM, Harrison MR, Shires TM (1997) Estimate of methane emissions from the US natural gas industry. Chemosphere 35: 1365-1390

Kruuskraa VA (2004) Tight gas sands development-How to dramatically improve recovery efficiency. GasTIPS, Winter 2004. http://media.godashboard.com/gti/4ReportsPubs/4_7GasTips/ Winter04/TightGasSandsDEvelopment-HowToDramaticallyImproveRecoveryEfficiency.pdf

Lassey KR, Lowe DC, Smith AM (2007) The atmospheric cycling of radiomethane and the "fossil fraction" of the methane source. Atmos Chem Phys 7:2141-2149

Lelieveld J, Lechtenbohmer S, Assonov SS, Brenninkmeijer CAM, Dinest C, Fischedick M, Hanke $\mathrm{T}$ (2005) Low methane leakage from gas pipelines. Nature 434:841-842

Liu AE (2008) Overview: pipeline accounting and leak detection by mass balance, theory and hardware implementation. Quantum Dynamics, Woodland Hills. Available at http://www.pstrust.org/ library/docs/massbalance_ld.pdf

National Research Council (2009) Hidden costs of energy: unpriced consequences of energy production and use. National Academy of Sciences Press, Washington

New York Department of Environmental Conservation (2009) Draft supplemental generic environmental impact statement on the oil, gas and solution mining regulatory program. http://www. dec.ny.gov/energy/58440.html

Nisbet EG, Manning MR, Lowry D, Lassey KR (2000) Methane and the framework convention on climate change, A61F-10, Eos Trans. AGU 81(48), Fall Meet. Suppl

Pacala S, Socolow R (2004) Stablization wedges: solving the climate problem for the next 50 years with current technologies. Science 305:968-972

Percival P (2010) Update on "lost and unaccounted for" natural gas in Texas. Basin Oil and Gas. Issue 32. http://fwbog.com/index.php?page $=$ article \&article $=248$

Reshetnikov AI, Paramonova NN, Shashkov AA (2000) An evaluation of historical methane emissions from the Soviet gas industry. JGR 105:3517-3529

Revkin A, Krauss C (2009) By degrees: curbing emissions by sealing gas leaks. New York Times, 14 October 2009. Available at http://www.nytimes.com/2009/10/15/business/energy-environment/ 15degrees.html

Samuels J (2010) Emission reduction strategies in the greater natural buttes. Anadarko Petroleum Corporation. EPA Gas STAR, Producers Technology Transfer Workshop Vernal, Utah, 23 March 2010. http://www.epa.gov/gasstar/documents/workshops/vernal-2010/03_anadarko.pdf

Santoro R, Howarth RW, Ingraffea T (2011) Life cycle greenhouse gas emissions inventory of Marcellus shale gas. Technical report of the Agriculture, Energy, \& Environment Program, Cornell University, Ithaca, NY. To be archived and made available on-line

Shindell DT, Faluvegi G, Koch DM, Schmidt GA, Unger N, Bauer SE (2009) Improved attribution of climate forcing to emissions. Science 326:716-718

Shires TM, Loughran, CJ, Jones S, Hopkins E (2009) Compendium of greenhouse gas emissions methodologies for the oil and natural gas industry. Prepared by URS Corporation for the American Petroleum Institute (API). API, Washington DC

Wood R, Gilbert P, Sharmina M, Anderson K, Fottitt A, Glynn S, Nicholls F (2011) Shale gas: a provisional assessment of climate change and environmental impacts. Tyndall Center, University of Manchester, Manchester, England. http:/www.tyndall.ac.uk/sites/default/files/tyndallcoop_shale_gas_report_final.pdf 